\title{
85 \\ RADIOFREQUENCY ABLATION PLUS VERTEBROPLASTY IN THE TREATMENT OF SYMPTOMATIC VERTEBRAL HEMANGIOMAS WITHOUT NEUROLOGICAL DEFICIT
}

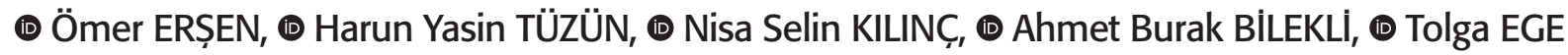

Gülhane Training and Research Hospital, Clinic of Orthopedics, Ankara, Turkey

\begin{abstract}
Objective: The most common benign neoplasms of the spine are vertebral hemangiomas (VH). This study aims to demonstrate the safety of radiofrequency (RF) ablation plus vertebroplasty in the treatment of $\mathrm{VHs}$.

Materials and Methods: The records of patients who underwent percutaneous RF ablation and vertebroplasty for the treatment of symptomatic VH between 2016 and 2018 were retrospectively reviewed and included in this study. The visual analogue scale (VAS) was used to measure the pain immediately after the procedure and in the first and sixth postoperative months.

Results: The average follow-up period was 23.6 months. The average duration of the procedure was 45.7 min. VAS score with activity was $5.29 \pm 1.2$ before the operation and improved to $2.14 \pm 1.3$ immediately after the operative $(p=0.0309)$. It was $0.7 \pm 0.3$ in the first month and $0.3 \pm 0.2$ in the sixth month postoperatively $(\mathrm{p}=0.0010)$.

Conclusion: Although only $1 \%$ of all VHs become symptomatic, symptomatic VHs cause disability during daily life. RF ablation plus vertebroplasty can be used separately in the treatment of symptomatic VHs.

Keywords: Radiofrequency ablation, vertebroplasty, vertebral haemangioma
\end{abstract}

\section{INTRODUCTION}

The most common benign neoplasms of the spine are vertebral hemangiomas (VH). VHs can be defined as benign vascular lesions with an incidence of $10-12 \%(1-6)$. In general, VHs are asymptomatic and no specific treatment is needed. Only $1 \%$ of $\mathrm{VH}$ s cause axial pain and rarely cause compression fractures ${ }^{(2,3,6-8)}$. If $\mathrm{VH}$ extends to the spinal canal or a compression fracture occurs, neurologic injury may be possible ${ }^{(4,9)}$.

The treatment methods of symptomatic VHs include vertebroplasty, embolization, ablation, radiotherapy and radiosurgery ${ }^{(1,3,10,11)}$. There are several ablation methods for vertebral tumours. Radiofrequency (RF) ablation, cryoablation, laser ablation, microwave ablation and alcohol ablation are minimally invasive treatment options ${ }^{(11-15)}$. RF ablation probes are inserted via percutaneous transpedicular guides. The tip of the probe produces frictional heat by charged tissue molecules. When the local temperature rises to $60^{\circ} \mathrm{C}-100^{\circ} \mathrm{C}$, protein denaturation and coagulative necrosis occur ${ }^{(11)}$. In vertebroplasty, polymethylmethacrylate (PMMA) is injected under fluoroscopic guidance to ensure support to the weak vertebral body ${ }^{(3,16)}$. In this study, we present our results of RF ablation combined with vertebroplasty in the treatment of symptomatic VHs.

\section{MATERIALS AND METHODS}

The records of patients who underwent percutaneous RF ablation and vertebroplasty for the treatment of symptomatic VHs between 2016 and 2018 were retrospectively reviewed and are included in this study. Fourteen patients were operated for a total of 16 levels of disease. All patients had axial pain resistant to conservative treatment.

Their symptomatic level was determined by a physical examination. Radiological evaluation was performed using plain X-rays, computed tomography and magnetic resonance imaging for all patients.

All procedures were performed under general anaesthesia with fluoroscopic guidance. Based on the radiological evaluation before the procedure, the easiest percutaneous transpedicular approach was determined and the guides were inserted.Biopsies

Address for Correspondence: Ömer Erşen, Gülhane Training and Research Hospital, Clinic of Orthopedics, Ankara, Turkey E-mail: merschenn@yahoo.com Received: 03.03.2020 Accepted: 20.04.2020

ORCID ID: orcid.org/0000-0001-7351-6305 
were routinely performed for all levels. Once the exact position of the guides was verified, the thermocouple was inserted. The tip of the electrode conducts the current that oscillates in the high frequency range (average, $480 \mathrm{kHz}$ ). RF ablation was performed with impedance and temperature controls. The procedure was immediately stopped if the proximal temperature reached $45^{\circ} \mathrm{C}$. When the tissue impedance decreased, the procedure was stopped. Under fluoroscopic control, PMMA was filled into the created cavity as much as possible. In case cement leakage was noticed, the injection was stopped (Figure 1).

The visual analogue scale (VAS) was used to assess the pain of the patients. VAS scores were obtained on the day of the treatment, immediately after the treatment and in the first and sixth postoperative months. The approach (unipedicular/ bipedicular), duration of the procedure, amount of cement injected, cement leakage, complications and analgesic use were recorded.

\section{Statistical Analysis}

For statistical analyses, the Kolmogorov-Smirnov test was used to evaluate whether the distribution of continuous variables was normal. For parameters that showed normal distribution, the paired sample t-test was used. For parameters that did not show normal distribution, the Mann-Whitney $U$ test was used. The chi-square test was used to analyse categorical variables. Statistical significance was set at $p<0.05$.

\section{RESULTS}

Fourteen patients (10 females, four males) with VHs with an average age of 48.5 years were treated using RF ablation and vertebroplasty. The average follow-up period was 23.6 months. The number of treated levels was 16, and two levels were operated by a bipedicular approach to get access to the whole lesion. Three lesions were located in the lower thoracic spine; the others were located in the lumbar spine. The average duration of the procedure was $45.7 \mathrm{~min}$ (40 min per level). The average amount of cement injected was $3 \mathrm{cc}$. Cement leakage to the intervertebral disc occurred for two levels. No cement leakage occurred towards the spinal canal. The biopsy samples confirmed the preoperative diagnosis as $\mathrm{VH}$ for all levels.

VAS score with activity was $5.29 \pm 1.2$ before the operation and improved to $2.14 \pm 1.3$ immediately after the operation $(p=0.0309)$. It was $0.7 \pm 0.3$ in the first month and $0.3 \pm 0.2$ in the

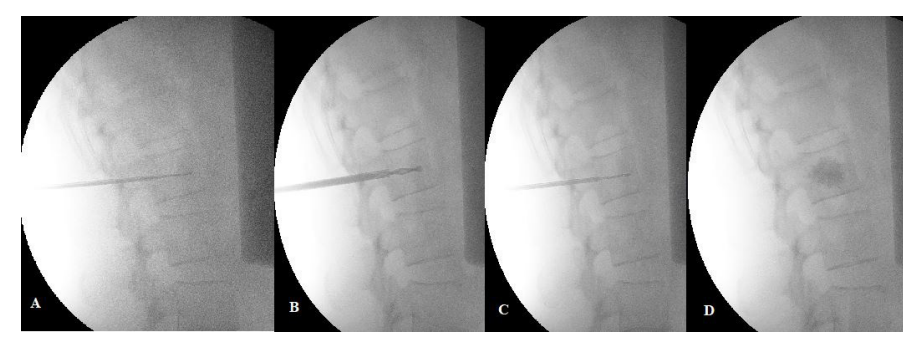

Figure 1. A) Insertion of the guidewire. B) Obtaining biopsy samples from the lesion. C) Radiofrequency probe insertion and ablation. D) Vertebroplasty sixth month postoperatively ( $p=0.001)$. At the final follow-up, only two patients reported that they rarely needed analgesics.

\section{DISCUSSION}

VHs are benign lesions that rarely become symptomatic unless they behave like an aggressive tumour and extend to the spinal canal and posterior elements of the spine. The most common symptom is axial pain ${ }^{(3,4,6,9)}$. Numerous methods are used in the treatment of symptomatic VHs. In this study, we present a combination of RF ablation and vertebroplasty for the treatment of symptomatic $\mathrm{VHs}^{(1,3,3,7,111)}$.

RF ablation is one of the most effective, minimally invasive ablation techniques for the treatment of VHs. The use of RF ablation was first reported in 1990 as a treatment for hepatic tumours. This study demonstrated that RF ablation is a safe and effective treatment option for $\mathrm{VHs}$. Real-time monitoring of the temperature of the spinal canal and intact cortical bone of the vertebral body provides the surgeon comfort, convenience and confidence during the operation. Moreover, RF ablation can even be used in malignancies to safely destroy the bone cortex $^{(7,11,17-19)}$. No complications associated with RF ablation were observed in any of the patients in this study.

Vertebroplasty is one of the most common treatment options for symptomatic $\mathrm{VH}^{(3,20)}$. Vertebral augmentation with PMMA is done under fluoroscopic guidance. With cement polymerisation, the exothermic reaction causes tumour necrosis. Cement itself ensures mechanical stability of the vertebral body and prevents vertebral collapse $\mathrm{e}^{(3,16)}$. Cement leakage is the most common complication of vertebroplasty, and the risk is high in $\mathrm{VHs}$ due to anomalous intervertebral vascularisation ${ }^{(3)}$. In this study, RF ablation of the lesion destroyed the dilated vessels and created space for cement injection. The combined procedure enabled a safer treatment option. Intradiscal cement leakages occurred for two levels where the lesions were about to destruct the endplates.

\section{Study Limitations}

Alcohol ablation can be used for the treatment of VHs. The main limitation of this treatment is inadequate control of the ablation zone and diffusion of the alcohol in the tissue, which can lead to neurological complications ${ }^{(15,21)}$. The embolisation of the lesion can reduce intraoperative blood loss in aggressive $\mathrm{VHs}^{(22)}$. In this study, the lesions were limited to the vertebral body and were small in size. As a result of this, we did not need to perform embolisation of the lesions. Radiotherapy is another treatment method for $\mathrm{VHs}$ that can be administered in a single high dose or fractionated doses. This method offers effective pain and tumour control, but good results are dose-dependent. Moreover, pain control after radiotherapy treatment requires 3-6 months ${ }^{(23,24)}$. In this study, patients achieved pain control immediately after the procedure. VAS scores decreased more than 3 points on the first day of the treatment.

The major limitations of this study are its retrospective design and small sample size. The reason for the small sample size 
is that there are payment limitations of the national social security institution. Further, our treatment method is only suitable for lesions limited to the vertebral body.

\section{CONCLUSION}

Although only $1 \%$ of all $\mathrm{VHs}$ become symptomatic, they can cause disability during daily life. RF ablation plus vertebroplasty can be used separately in the treatment of symptomatic VHs. In this study, we used both methods and demonstrated the safety of this combined treatment.

\section{Ethics}

Ethics Committee Approval: Ethical approval have not been taken for the retrospective study.

Informed Consent: Informed consent was obtained from the patients.

\section{Authorship Contributions}

Surgical and Medical Practices: Ö.E., H.Y.T., N.S.K., A.B.B., T.E., Concept: Ö.E., H.Y.T., T.E., Design: Ö.E., N.S.K., Data Collection or Processing: H.Y.T., N.S.K., Analysis or Interpretation: Ö.E., N.S.K., A.B.B., Literature Search: Ö.E., H.Y.T., N.S.K., Writing: Ö.E., A.B.B., T.E.

Conflict of Interest: No conflict of interest was declared by the authors.

Financial Disclosure: The authors declared that this study received no financial support.

\section{REFERENCES}

1. Koch G, Cazzato RL, Gilkison A, Caudrelier J, Garnon J, Gangi A. Percutaneous Treatments of Benign Bone Tumors. Semin Intervent Radiol. 2018;35:324-2.

2. Fox MW, Onofrio BM. The natural history and management of symptomatic and asymptomatic vertebral hemangiomas. J Neurosurg. 1993; 78:36-45.

3. Liu XW, Jin P, Wang LJ, Li M, Sun G. Vertebroplasty in the treatment of symptomatic vertebral haemangiomas without neurological deficit. Eur Radiol. 2013; 23:2575-81.

4. Cloran FJ, Pukenas BA, Loevner LA, Aquino C, Schuster J, Mohan $S$. Aggressive spinal haemangiomas: imaging correlates to clinical presentation with analysis of treatment algorithm and clinical outcomes. Br J Radiol. 2015;88:20140771.

5. Murphey MD, Fairbairn KJ, Parman LM, Baxter KG, Parsa MB, Smith WS. Musculoskeletal angiomatous lesions: radiologic-pathologic correlation. Radiographics. 1995;15:893-917.

6. Chen HI, Heuer GG, Zaghloul K, Simon SL, Weigele JB, Grady MS. Lumbar vertebral hemangioma presenting with the acute onset of neurological symptoms. Case report. J Neurosurg Spine. 2007;7:80-5.
7. Jiang L, Liu XG, Yuan HS, Yang SM, Li J, Wei F, et al. Diagnosis and treatment of vertebral hemangiomas with neurologic deficit: a report of 29 cases and literature review. Spine J. 2014;14:944-54.

8. Korkmaz MF, Saraç K, Karakaplan M, Görmeli G, Erdem MN, Selçuk EB. Evaluation of the Efficacy and Safety of Surgical Treatment of Multilevel Vertebral Hemangiomas Causing Cord Compression. J Turk Spinal Surg. 2014;25:211-8.

9. Acosta FL Jr, Sanai N, Chi JH, Dowd CF, Chin C, Tihan T, et al. Comprehensive management of symptomatic and aggressive vertebral hemangiomas. Neurosurg Clin N Am. 2008;19:17-29.

10. Kelley SP, Ashford RU, Rao AS, Dickson RA. Primary bone tumours of the spine: a 42-year survey from the Leeds Regional Bone Tumour Registry. Eur Spine J. 2007; 16:405-9.

11. Tomasian A, Wallace AN, Jennings JW. Benign Spine Lesions: Advances in Techniques for Minimally Invasive Percutaneous Treatment. AJNR Am J Neuroradiol. 2017;38:852-61.

12. Gage AA, Baust JG. Cryosurgery for tumors. J Am Coll Surg 2007; 205:342-56.

13. Rybak LD, Gangi A, Buy X, La Rocca Vieira R, Wittig J. Thermal ablation of spinal osteoid osteomas close to neural elements: technical considerations. AJR Am J Roentgenol. 2010;195:293-8.

14. Kastler A, Alnassan H, Aubry S, Alemann G, Barbe D, Aubry S, et al. Microwave thermal ablation of spinal metastatic bone tumors. J Vasc Interv Radiol. 2014;25:1470-5.

15. Gangi A, Buy X. Percutaneous bone tumor management. Semin Intervent Radiol 2010;27:124-36.

16. Guarnieri G, Ambrosanio G, Vassallo P, Vassalo P, Pezzullo MG, Galasso $\mathrm{R}$, et al. Vertebroplasty as treatment of aggressive and symptomatic vertebral hemangiomas: Up to 4 years of follow-up. Neuroradiology. 2009;51:471-6.

17. Masala S, Roselli M, Massari F, Fiori R, Ursone A, Fossile E, et al. Radiofrequency Heat Ablation and Vertebroplasty in the treatment of neoplastic vertebral body fractures. Anticancer Res. 2004;24:3129-33.

18. Nakatsuka A, Yamakado K, Takaki H, Uraki J, Makita M, Oshima F, et al. Percutaneous radiofrequency ablation of painful spinal tumors adjacent to the spinal cord with real-time monitoring of spinal canal temperature: a prospective study. Cardiovasc Intervent Radiol. 2009;32:70-5.

19. Bagla S, Sayed D, Smirniotopoulos J, Brower J, Rutledge JR, Dick B, et al. Multicenter Prospective Clinical Series Evaluating Radiofrequency Ablation in the Treatment of Painful Spine Metastases. Cardiovasc Intervent Radiol. 2016;39:1289-97.

20. Hao J, Hu Z. Percutaneous cement vertebroplasty in the treatment of symptomatic vertebral hemangiomas. Pain Physician. 2012;15:43-49.

21. Doppman JL, Oldfield EH, Heiss JD. Symptomatic vertebral hemangiomas: treatment by means of direct intralesional injection of ethanol. Radiology. 2000;214:341-8.

22. Berkefeld J, Scale D, Kirchner J. Hypervascular spinal tumors: influence of the embolization technique on perioperative hemorrhage. AJNR Am J Neuroradiol. 1999;20:757-63.

23. Miszczyk L, Tukiendorf A. Radiotherapy of painful vertebral hemangiomas: the single center retrospective analysis of 137 cases. Int J Radiat Oncol Biol Phys. 2012;82:e173-80.

24. Parekh AD, Amdur RJ, Mendenhall WM, Morris CG, Zlotecki RA. Longterm Tumor Control With Radiotherapy for Symptomatic Hemangioma of a Vertebral Body. Spine (Phila Pa 1976). 2019;44:E731-4. 